\title{
Efeito de fontes e doses de nitrogênio na produção e qualidade da forragem de capim-coastcross ${ }^{1}$
}

\author{
Luciano de Almeida Corrêa ${ }^{2}$, Heitor Cantarella ${ }^{3}$, Ana Cândida Primavesi ${ }^{2}$, Odo Primavesi ${ }^{2}$, \\ Alfredo Ribeiro de Freitas ${ }^{2}$, Aliomar Gabriel da Silva ${ }^{2}$ \\ ${ }^{1}$ Financiamento: Convênio Embrapa-Petrobrás. \\ 2 Embrapa Pecuária Sudeste, Caixa Postal 339, CEP: 13560-970, São Carlos, SP, Brasil. \\ 3 Instituto Agronômico de Campinas, Centro de Solos e Recursos Agroambientais, Caixa Postal 28, CEP: 13001-970, Campinas, SP.
}

RESUMO - A produção e a qualidade da forragem do capim-coastcross cultivado em Latossolo Vermelho Distroférrico foram avaliadas no período de novembro a abril dos anos de 1998-1999 e 1999-2000, em São Carlos, SP, sob clima tropical de altitude. O delineamento experimental utilizado foi o de blocos casualizados, com quatro repetições, em parcelas subdivididas. Nas parcelas foram distribuídos dez tratamentos, organizados em esquema fatorial 2 x 5 (duas fontes de nitrogênio: uréia e nitrato de amônia; e cinco doses: $0,25,50,100,200 \mathrm{~kg} \mathrm{~N} / \mathrm{ha} /$ corte, em cinco cortes consecutivos - medidas repetidas). $\mathrm{Na}$ análise, utilizaram-se o procedimento MIXED do SAS e o modelo misto usual para análises de medidas repetidas. A adubação nitrogenada aumentou a produção de MS, o teor de $\mathrm{PB}$, a digestibilidade in vitro da MS e o teor de nitrato e reduziu os teores de MS e FDN na forragem do capim-coastcross. No primeiro ano, as doses de $\mathrm{N}$ associadas a $80 \%$ da produção máxima de forragem foram de 88 e $78 \mathrm{~kg} \mathrm{~N}$ ha/corte, correspondendo a produções de MS de 2.769 e $3.202 \mathrm{~kg} \mathrm{~N} / \mathrm{ha} /$ corte, respectivamente, para uréia e nitrato de amônio. No segundo ano, as doses foram de 91 e $116 \mathrm{~kg} \mathrm{~N} / \mathrm{ha} /$ corte e resultaram em produções de MS de 2.312 e $3.072 .8 \mathrm{~kg} \mathrm{~N} / \mathrm{ha} /$ corte, na mesma ordem.

Palavras-chave: gramínea tropical, nitrato de amônia, proteína bruta, valor nutritivo, uréia

\section{Effects of sources and rates of nitrogen on forage production and quality of coastcrossgrass}

\begin{abstract}
Forage production and quality of coastcross grown on a dark red latosol (Hapludox) were evaluated in 1998-1999 and 1999-2000, from November to April, in São Carlos, São Paulo state, Brazil, under a tropical altitude climate. The experimental design was a randomized block design, in a split-plot arrangement, with four replications. In the main plots were allocated ten treatments, organized in a $2 \times 5$-factorial scheme (two nitrogen sources: urea and ammonium nitrate, and five N levels: $0,25,50,100$, and $200 \mathrm{~kg} \mathrm{~N} / \mathrm{ha} / \mathrm{cutting}$, in five consecutive cuttings - repeated measures). Data were analyzed by MIXED procedure of SAS, using a repeated measure model. Nitrogen fertilization increased DM yield, CP concentration, in vitro DM digestibility, and nitrate concentration, and reduced DM and NDF concentrations in the forage. In the first year, $\mathrm{N}$ doses associated with $80 \%$ of the maximum forage yield were 88 and $78 \mathrm{~kg} / \mathrm{ha}$, corresponding to average dry matter yields of 2,769 and 3,202 kg N/ha/cutting, respectively, for urea and ammonium nitrate. In the second year, $\mathrm{N}$ doses which produced $80 \%$ of the maximum forage yield were 91 and $116 \mathrm{~kg} / \mathrm{ha}$, respectively, for urea and ammonium nitrate, corresponding to average DM yields of 2,312 and 3,073 kg ha/cutting, respectively.
\end{abstract}

Key Words: ammonium nitrate, crude protein, nutritive value, tropical grass, urea

\section{Introdução}

Embora as gramíneas forrageiras tropicais não possuam qualidade nutricional comparável à de gramíneas de clima temperado, seu elevado potencial de produção de MS pode resultar em alta produtividade animal. Para que as gramíneas expressem esse potencial, a aplicação de altas doses de adubo nitrogenado é um dos fatores mais importantes. Vicente-Chandler et al. (1959) encontraram resposta positiva à aplicação de até $1.800 \mathrm{~kg} \mathrm{~N} / \mathrm{ha} / \mathrm{ano}$. Outros autores, entretanto, demonstraram que as maiores respostas são obtidas com doses de 300 a $400 \mathrm{~kg} \mathrm{~N} / \mathrm{ha} / \mathrm{ano}$ (Werner et al., 1967; Olsen, 1972; Gomes et al., 1987). As respostas, no caso do capim-coastcross, dependem do manejo e podem ser crescentes, de até $500 \mathrm{~kg} \mathrm{~N} / \mathrm{ha} /$ ano (Alvim et al., 1998).

Entre as fontes de N, a uréia tem sido a de menor eficiência em grande número de culturas, em diferentes 
solos e climas, por diversas causas, como volatilização de $\mathrm{NH}_{3}$, lixiviação de $\mathrm{N}_{3}^{-}$e seu efeito tóxico sobre as plantas no início do período vegetativo. Porém, em muitos ensaios, a uréia tem-se mostrado igual ou superior aos outros fertilizantes (Mello, 1987). Pesquisas têm comprovado que a eficiência agronômica de fontes de adubos nitrogenados é semelhante quando incorporadas ao solo.

Dessa forma, há interesse em estudos que visam estabelecer a fonte mais eficiente e a dose mais adequada para pastagens manejadas intensivamente, em especial quando a uréia é aplicada superficialmente, em razão das perdas de $\mathrm{NH}_{3}$ por volatilização. Whitehead (1995) verificou em pastagens perdas de $\mathrm{N}$ da uréia que variavam de 2 a $36 \%$, com média de perdas de $20 \%$. Por outro lado, a adubação nitrogenada também pode ter reflexos na qualidade da forragem produzida. Alvim et al. (1996), em ensaio com capim-coastcross, verificaram aumentos lineares no teor de proteína em resposta a doses de até $750 \mathrm{~kg}$ de N/ha/ano, porém, não constataram resposta do teor de FDN. Na literatura, os resultados sobre o efeito de doses de $\mathrm{N}$ na digestibilidade in vitro da MS (DIVMS) são conflitantes (Monson \& Burton, 1982; Gomide \& Costa, 1984; Nussio et al., 1998; Cáceres et al., 1989). Além disso, a adubação nitrogenada utilizada em doses altas pode reduzir a qualidade da forragem para bovinos, haja vista a possibilidade de acúmulo de níveis tóxicos de nitrato na forragem (Olsen, 1972).

Este trabalho foi realizado com o objetivo de verificar o efeito de fontes e de doses de $\mathrm{N}$ utilizadas na adubação sobre a produção e a qualidade da forragem de capimcoastcross.

\section{Material e Métodos}

Os experimentos foram realizados em parte de uma pastagem de capim-coastcross (Cynodon dactylon cv. Coastcross) em Latossolo Vermelho Distroférrico típico, com 30\% de argila, na Embrapa Pecuária Sudeste, em São Carlos, SP, Brasil $\left(22^{\circ} 01^{\prime} \mathrm{S}, 47^{\circ} 54^{\prime} \mathrm{W}\right.$ e altitude de $\left.836 \mathrm{~m}\right)$, sob clima tropical de altitude. A pastagem era utilizada há cinco anos, com bovinos de corte, sob sistema de pastejo rotacionado, com elevada dose de adubo.

As características químicas do solo na camada de 0 a $20 \mathrm{~cm}$ no início do experimento foram as seguintes: $\mathrm{pH}$ em $\mathrm{CaCl}_{2}$ : 5,6; MO: $32 \mathrm{~g} / \mathrm{dm}^{3}$; P disponível: $27 \mathrm{mg} / \mathrm{dm}^{3}$; K disponível: $5,1 \mathrm{mmol}_{\mathrm{c}} / \mathrm{dm}^{3}$; Ca trocável: $25 \mathrm{mmol}_{\mathrm{c}} / \mathrm{dm}^{3}$; $\mathrm{Mg}$ trocável: $14 \mathrm{mmol} / \mathrm{dm} 3$; capacidade de troca catiônica: $65 \mathrm{mmol} / \mathrm{dm}^{3}$; e saturação por bases: $67 \%$. Para elevar a saturação por bases para $70 \%$ da capacidade de troca catiônica, aplicou-se calcário. Adubos foram aplicados na dose de $100 \mathrm{~kg} \mathrm{P}_{2} \mathrm{O}_{5} /$ ha como superfosfato simples e de $30 \mathrm{~kg} / \mathrm{ha}$ de micronutrientes FTE BR-12. O potássio foi aplicadona forma de $\mathrm{KCl}$ junto com as adubações de $\mathrm{N}$ para repor a quantidade removida pelos cortes e manter o nível mínimo de $20 \mathrm{~g}$ de $\mathrm{K} / \mathrm{kg}$ de MS de forragem. Foram utilizadas duas áreas distintas: a primeira no período de novembro de 1998 a abril de 1999 e a segunda no período de 1999 a 2000.

Odelineamento experimental foi o de blocos casualizados, com quatro repetições, em parcelas subdivididas. Os tratamentos aplicados nas parcelas foram sorteados em esquema fatorial $2 \times 5$ (duas fontes de $\mathrm{N}$ : uréia e nitrato de amônio; e cinco doses de $\mathrm{N}$ : 0, 25, 50,100, $200 \mathrm{~kg} \mathrm{~N} / \mathrm{ha} /$ corte); nas subparcelas, foram considerados cinco cortes consecutivos. $\mathrm{O} \mathrm{N}$ foi aplicado após cada corte, durante a estação das chuvas. $O$ tamanho das parcelas foi de $4 \times 5 \mathrm{~m}$ e a avaliação da produção de forragem foi feita em área útil de $6 \mathrm{~m}^{2}$. A forrageira foi cortada a $10 \mathrm{~cm}$ da superfície do solo, com intervalo médio de 30 dias. Após a determinação da matéria fresca de forragem de cada parcela, foi retirada, aleatoriamente, uma amostra com $500 \mathrm{~g}$, a qual foi seca em estufa de circulação forçada, a $60^{\circ} \mathrm{C}$, até obter massa constante para determinação do teor de água e cálculo da massa da MS.

A análise de nitrato na planta foi feita segundo Tedesco et al. (1985). A DIVMS foi determinada segundo o método de Tilley \& Terry, descrito por Silva (1981). No cálculo da FDN, foi utilizado o método descrito por Souza et al. (1999).

Adotando-se o delineamento experimental em blocos ao acaso, com parcelas subdivididas, a análise dos dados foi feita por meio do procedimento MIXED do SAS utilizando-se o modelo misto usual para análise de medidas repetidas (Littell et al., 1996, 1998), determinado por:

$$
\mathrm{y}_{\mathrm{ijk}}=\mu+\alpha_{\mathrm{i}}+\delta_{\mathrm{ij}}+\tau_{\mathrm{k}}+(\delta \tau)_{\mathrm{ik}}+\varepsilon_{\mathrm{ijk}},
$$

em que $\mathrm{y}_{\mathrm{ijk}}=$ resposta no corte $\mathrm{k}$ na unidade experimental $\mathrm{j}$, no grupo de tratamento aplicado às parcelas $\mathrm{i} ; \mu=$ média global; $\alpha_{i}=$ efeito fixo do grupo de tratamento i aplicado às parcelas; $\delta_{\mathrm{ij}}=$ efeito aleatório da unidade experimental $\mathrm{j}$ no grupo de tratamento $\mathrm{i} ; \tau_{\mathrm{k}}=$ efeito fixo do corte $\mathrm{k} ;(\delta \tau)_{\mathrm{ik}}=$ efeito de interação; $\varepsilon_{i j k}=$ erro aleatório no corte $\mathrm{k}$, no indivíduo j e no grupo de tratamento i.

As estruturas de covariâncias de medidas repetidas envolvem os termos $\delta_{\mathrm{ij}}$ e $\varepsilon_{\mathrm{ijk}}$. Os primeiros são considerados independentes, enquanto os $\varepsilon_{i j k}$ são correlacionados e refletem a variação dentro da unidade experimental, determinada por $\mathrm{V}\left(\varepsilon_{\mathrm{ijk}}\right)=\mathrm{R}$. Uma das grandes contribuições do procedimento MIXED do SAS em análises de medidas repetidas é permitir, entre várias estruturas de covariâncias, selecionar aquela que melhor se ajusta aos dados. Neste trabalho, foram testadas as estruturas auto-regressiva de primeira ordem, não-estruturada, simetria composta e 
simetria composta heterogênea e de Toeplitz (SAS). Como critério de seleção, foi utilizado o Akaike's information criterion, $\mathrm{AIC}=-2 \mathrm{~L}_{\mathrm{R}}+2 \mathrm{q}$, em que $\mathrm{L}_{\mathrm{R}}$ é o logaritmo da função de máxima verossimilhança restrita avaliada no ponto de máximo (Wolfinger, 1993) e q, a dimensão do modelo.

\section{Resultados e Discussão}

Na forma fornecida pelo procedimento MIXED do SAS, se os valores de AIC são positivos, as estruturas de covariâncias associadas aos menores valores são as mais apropriadas (Tabelas 1 e 2). Assim, para os dados de 19981999 (Tabela 1), as estruturas de covariâncias mais adequadas foram a não-estruturada, para produção de MS (PMS), teor de MS, teor de PB, DIVMS e teor de nitrato
$\left(\mathrm{N}-\mathrm{NO}_{3}\right)$; e a simetria composta heterogênea, para FDN. Para os dados de 1999-2000 (Tabela 2), as estruturas mais apropriadas foram anão estruturada, para teores deFDNe de $\mathrm{N}-\mathrm{NO}_{3}$; a auto-regressiva de primeira ordem, para PMS e DIVMS; a simetria composta, para teor de PB; e Toepliz, para teor de MS.

Nos testes de efeitos fixos do tipo 3 do modelo misto utilizado (Tabela 3), os efeitos principais de doses e de cortes foram significativos para todas as variáveis analisadas, enquanto os efeitos de fontes de nitrogênio não o foram para FDN e DIVMS. As interações fontes $\times$ doses $\times$ cortes, fontes $\times$ doses, fontes $\times$ cortes e doses $\times$ cortes, nessa ordem, apresentaram importância decrescente quanto à significância dos efeitos.

Observaram-se diferenças significativas $(\mathrm{P}<0,0001)$ entre as fontes de $\mathrm{N}$, com superioridade do nitrato de

Tabela 1 - Valores do logaritmo da função de máxima verossimilhança restrita (log L) obtidos para o AIC (Akaike's Information Criterion) nas análises de varáveis avaliadas em capim-coastcross em 1998-1999

Table 1 - Values of the $\log$ of REML (log L) obtained for Akaike's information criterion of traits evaluated in coastcross grass in $1998-1999$

\begin{tabular}{|c|c|c|c|c|c|c|}
\hline \multirow{2}{*}{$\begin{array}{l}\text { Estrutura de covariância } \\
\text { Covariance structure }\end{array}$} & \multicolumn{6}{|c|}{$\log L$} \\
\hline & $\begin{array}{l}\text { PMS } \\
D M Y\end{array}$ & $\begin{array}{l}\text { MS } \\
D M\end{array}$ & $\begin{array}{l}\mathrm{PB} \\
C P\end{array}$ & $\begin{array}{l}\text { FDN } \\
N D F\end{array}$ & $\begin{array}{l}\text { DIVMS } \\
\text { IVDMD }\end{array}$ & $\begin{array}{l}\mathrm{N}-\mathrm{NO}_{3} \\
\mathrm{~N}-\mathrm{NO}_{3} \\
\end{array}$ \\
\hline $\begin{array}{l}\text { Simetria composta heterogênea } \\
\text { Heterogeneous compound symmetry }\end{array}$ & $3.325,4$ & 591,1 & 694,1 & 834,4 & 990,8 & $2.603,0$ \\
\hline $\begin{array}{l}\text { Não-estruturada } \\
\text { Unstructured }\end{array}$ & $3.159,0$ & 571,9 & 664,8 & 847,3 & 969,2 & $2.493,5$ \\
\hline $\begin{array}{l}\text { Simetria composta } \\
\text { Compound symmetry }\end{array}$ & $3.391,6$ & 627,4 & 733,1 & 851,8 & $1.062,8$ & $2.621,1$ \\
\hline Auto-regressiva de primeira ordem & $3.173,4$ & 621,4 & 735,1 & 852,9 & $1.038,4$ & $2.570,2$ \\
\hline $\begin{array}{l}\text { First-order autoregressive } \\
\text { Toeplitz }\end{array}$ & $3.177,0$ & 613,6 & 710.9 & 855,7 & $1.028,1$ & $2.546,9$ \\
\hline
\end{tabular}

PMS = produção de MS $(D M Y=$ dry matter yield $) ; \mathrm{DIVMS}=$ digestibilidade in vitro da $\mathrm{MS}\left(\right.$ IVDMD = in vitro DM digestibility); $\mathrm{N}-\mathrm{NO}_{3}=$ nitrato (nitrate).

Tabela 2 - Valores do logaritmo da função de máxima verossimilhança restrita (log L) obtidos para o AIC (Akaike's information criterion) nas análises de variáveis avaliadas em capim-coastcross em 1999-2000

Table 2- Values of the log of REML (log L) obtained for Akaike's information criterion of trais evaluated in coastcross grass in 1999 and 2000

Estrutura de covariância $\quad$ Log L

Covariance structure

$\log \mathrm{L}$

\begin{tabular}{|c|c|c|c|c|c|c|}
\hline & $\begin{array}{l}\text { PMS } \\
D M Y\end{array}$ & $\begin{array}{l}M S \\
D M\end{array}$ & $\begin{array}{l}\mathrm{PB} \\
C P\end{array}$ & $\begin{array}{l}\text { FDN } \\
N D F\end{array}$ & $\begin{array}{l}\text { DIVMS } \\
\text { IVDMD }\end{array}$ & $\begin{array}{l}\mathrm{N}-\mathrm{NO}_{3} \\
\mathrm{~N}-\mathrm{NO}_{3}\end{array}$ \\
\hline Simetria composta heterogênea & $2.972,7$ & 516,8 & 582,2 & 884,7 & - & $2.755,0$ \\
\hline $\begin{array}{l}\text { Heterogeneous compound symmetry } \\
\text { Não-estruturada } \\
\text { Unstructured }\end{array}$ & $2.964,7$ & - & 587,5 & 878,3 & 863,5 & $2.722,7$ \\
\hline $\begin{array}{l}\text { Simetria composta } \\
\text { Compound symmetry }\end{array}$ & $2.970,0$ & 512,9 & 582,0 & 886,6 & 853,2 & $2.816,2$ \\
\hline Auto-regressiva de primeira ordem & $2.954,6$ & 554,1 & 582,8 & 883,9 & 851,4 & $2.817,8$ \\
\hline $\begin{array}{l}\text { First-order autoregressive } \\
\text { Toeplitz }\end{array}$ & $2.956,2$ & 486,6 & 586.4 & 886,2 & 855,9 & $2.809,7$ \\
\hline
\end{tabular}

'-' = estrutura de covariância não se ajustou ('- ' = Covariance structure did not fit); PMS = produção de MS (DMY = dry matter yield); DIVMS = digestibilidade in vitro da $\mathrm{MS}$ (IVDMD = in vitro $D M$ digestibility); $\mathrm{N}-\mathrm{NO}_{3}=$ nitrato (nitrate). 
Tabela 3 - Testes dos efeitos fixos do tipo III, considerando duas fontes de $\mathrm{N}$ (uréia e nitrato de amônio), cinco doses de $\mathrm{N}(0,25,50$, 100 e $200 \mathrm{~kg} \mathrm{~N} / \mathrm{ha}$ /corte) e cinco cortes

Table 3 - $\quad$ Type 3 tests of fixed effects, considering two $\mathrm{N}$ sources (urea and ammonium nitrate), five rates of $\mathrm{N}\left(0,25,50,100\right.$, and $200 \mathrm{~kg}$ of $\mathrm{N} \mathrm{ha}{ }^{-1}$ ), and five cuts

\begin{tabular}{|c|c|c|c|c|c|c|c|c|c|c|c|c|}
\hline \multirow[b]{2}{*}{$\begin{array}{l}\text { Efeito } \\
\text { Effect }\end{array}$} & \multicolumn{6}{|c|}{ Ano (Year) 1998-1999 } & \multicolumn{6}{|c|}{ Ano (Year) 1999-2000 } \\
\hline & $\begin{array}{l}\text { PMS } \\
D M Y\end{array}$ & $\begin{array}{l}\text { MS } \\
D M\end{array}$ & $\begin{array}{l}\mathrm{PB} \\
C P\end{array}$ & $\begin{array}{l}\text { FDN } \\
N D F\end{array}$ & $\begin{array}{l}\text { DIVMS } \\
I V D M D\end{array}$ & $\begin{array}{c}\mathrm{N}-\mathrm{NO}_{3} \\
\mathrm{~N}-\mathrm{NO}_{3}\end{array}$ & $\begin{array}{l}\text { PMS } \\
D M Y\end{array}$ & $\begin{array}{l}\text { MS } \\
D M\end{array}$ & $\begin{array}{l}\mathrm{PB} \\
C P\end{array}$ & $\begin{array}{c}\text { FDN } \\
N D F\end{array}$ & $\begin{array}{l}\text { DIVMS } \\
I V D M D\end{array}$ & $\begin{array}{c}\mathrm{N}-\mathrm{NO}_{3} \\
\mathrm{~N}-\mathrm{NO}_{3}\end{array}$ \\
\hline Fontes (F) & & & & & & & & & & $\mathrm{ns}$ & $\mathrm{ns}$ & \\
\hline \multicolumn{13}{|l|}{ Sources $(F)$} \\
\hline \multicolumn{13}{|l|}{ Doses (D) } \\
\hline \multicolumn{13}{|l|}{ Rates $(D)$} \\
\hline Interação F × D & & $\mathrm{ns}$ & & & ns & & & $\mathrm{ns}$ & & & ns & \\
\hline \multicolumn{13}{|l|}{$F \times D$ interaction } \\
\hline \multicolumn{13}{|l|}{ Cortes (C) } \\
\hline \multicolumn{13}{|l|}{ Cuts $\odot$} \\
\hline Interação $\mathrm{F} \times \mathrm{C}$ & & & & & & & & & & $\mathrm{ns}$ & ns & $\mathrm{ns}$ \\
\hline \multicolumn{13}{|l|}{$F \times C$ interaction } \\
\hline Interação $\mathrm{D} \times \mathrm{C}$ & & & & & & & & $\mathrm{ns}$ & & & & \\
\hline \multicolumn{13}{|l|}{$D \times C$ interaction } \\
\hline Interação $\mathrm{F} \times \mathrm{D} \times \mathrm{C}$ & & & & $\mathrm{ns}$ & $\mathrm{ns}$ & & & $\mathrm{ns}$ & $\mathrm{ns}$ & & $\mathrm{ns}$ & $\mathrm{ns}$ \\
\hline
\end{tabular}

$\mathrm{PMS}=$ produção de $\mathrm{MS}(D M Y=D M$ yield $) ; \mathrm{DIVMS}=$ digestibilidade in vitro da $\mathrm{MS}\left(\right.$ IVDMD = in vitro $D M$ digestibility); $\mathrm{N}-\mathrm{NO}{ }_{3}=$ nitrato $($ nitrate $)$.

amônia (Tabela 4). Independentemente do número de cortes e do ano, a adubação nitrogenada em capim-coastcross até a dose de $200 \mathrm{~kg}_{\text {de }} \mathrm{N} \mathrm{ha}^{-1}$ aumentou significativamente $(\mathrm{P}<0,0001)$ a produção de MS. A média de PMS em kg/ha no tratamento testemunha, variou de $520,9 \pm 56,22$ a 810,1 $\pm 55,24 \mathrm{~kg} / \mathrm{ha} \mathrm{e}$, no tratamento com $200 \mathrm{~kg} \mathrm{~N} / \mathrm{ha} /$ corte, de $2844,7 \pm 56,22$ a $3612,4 \pm 55,24 \mathrm{~kg} / \mathrm{ha}$. Com ambas as fontes de N, ocorreram oscilações na PMS nos diferentes cortes. Resposta positiva do capim-coastcross à adubação nitrogenada foi constatada também por Palhano \& Haddad (1992) e Alvim et al. (1998).

Segundo Whitehead (1995), a deficiência de $\mathrm{N}$ restringe o potencial de perfilhamento das plantas forrageiras e, principalmente, limita o crescimento e o aparecimento de folhas individuais e a capacidade fotossintética. Assim, o crescimento da parte aérea é mais prejudicado que o das raízes.

Consta na Tabela 5, para cada fonte de nitrogênio e para cada ano agrícola (1998-1999 e 1999-2000), a estimativa de produção de MS obtida por meio de um modelo polinomial de até terceira ordem de doses de nitrogênio. No primeiro ano e na adubação com uréia, a PMS, em $\mathrm{kg} \mathrm{ha}^{-1}$, no tratamento testemunha, nos cortes de 1 a 5 , respectivamente, foi de 4,9;446,8; 587,9;2.201,0;734,7 e 800,2 e a produção máxima, de $1.302,9 ; 5.197,8 ; 4.955,9 ; 5.563,2$ e 3.333,0. Para a adubação com nitrato de amônia, a PMS da testemunha foi, respectivamente, de $0 ; 552,4 ; 466,2 ; 2.439,8$; 852,3 e 865,2 e a produção máxima, de 4.051,0; 4.974,6; $3.176,3 ; 5.732,4$ e $3.542,3$.

No segundo ano, a PMS, em kg ha-1 , na adubação com uréia, foi, respectivamente, de $0 ; 366,0 ; 269,3 ; 1.077,5 ; 234,7$
Tabela 4 - Estimativas da média e dos erros-padrão da produção de MS de capim-coastcross obtidas por quadrados mínimos considerando os efeitos principais de duas fontes de N (1 - uréia; e 2 - nitrato de amônia), cinco doses de $\mathrm{N}(0,25,50,100$ e $200 \mathrm{~kg} \mathrm{~N} /$ ha/corte $)$ e cinco cortes (1 a 5 )

Table 4 - Mean and standard error estimates of DM yield of coastcross grass obtained by least squares means, considering two $N$ sources: urea (1) and ammonium nitrate (2), five rates of $N(0,25,50,100$, and $200 \mathrm{~kg} \mathrm{~N} / \mathrm{ha})$, and five cuttings ( 1 to 5 )

\begin{tabular}{lccc}
\hline $\begin{array}{l}\text { Efeito** } \\
\text { Effect }\end{array}$ & $\begin{array}{c}\text { Nível } \\
\text { Level }\end{array}$ & $\begin{array}{c}\text { Ano: 1998-1999 } \\
\text { Year: 1998-1999 }\end{array}$ & $\begin{array}{c}\text { Ano: 1999-2000 } \\
\text { Year: 1999-2000 }\end{array}$ \\
\hline & $\overline{\mathrm{X}} \pm \mathrm{s}(\overline{\mathrm{X}})$ & $\overline{\mathrm{X}} \pm \mathrm{s}(\overline{\mathrm{X}})$ \\
\hline
\end{tabular}

\begin{tabular}{lrrr}
\hline $\begin{array}{l}\text { Fonte de N } \\
\text { N source }\end{array}$ & 1 & $2.147,9 \pm 34,93$ & $1704,9 \pm 35,55$ \\
& & & \\
& 2 & $2.511,6 \pm 34,93$ & $1.931,7 \pm 35,55$ \\
Dose (kg N/ha/corte) & & & \\
Rate $(\mathrm{kg} \mathrm{N} / \mathrm{ha} / \mathrm{cut})$ & 0 & $8.10,1 \pm 55,24$ & $520,9 \pm 56,22$ \\
& 25 & $1.606,2 \pm 55,24$ & $1.162,7 \pm 56,22$ \\
& 50 & $2.426,9 \pm 55,24$ & $1.932,3 \pm 56,22$ \\
& 100 & $3.193,1 \pm 55,24$ & $2.630,9 \pm 56,22$ \\
Corte & 200 & $3.612,4 \pm 55,24$ & $2.844,7 \pm 56,22$ \\
Cut & 1 & $9.13,1 \pm 57,67$ & $1.329,3 \pm 45,68$ \\
& 2 & $2.796,5 \pm 43,71$ & $1.769,9 \pm 45,68$ \\
& 3 & $1.688,8 \pm 47,68$ & $2.347,0 \pm 45,68$ \\
& 4 & $4.070,9 \pm 53,29$ & $1.411,8 \pm 45,68$ \\
& 5 & $2.179,4 \pm 43,02$ & $2.233,4 \pm 45,68$ \\
\hline
\end{tabular}

** $(P<0,0001)$ entre níveis dentro de efeitos principais.

** $(P<0.0001)$ between levels within main effects.

e 716,9 e as produções máximas, 2.331,0; 3.339,0; 3.407,9; $2.165,9$ e 3.529,9. Com a adubação com nitrato de amônia, a PMS no tratamento testemunha foi, respectivamente, de 44,$3 ; 106,5 ; 1.098,9 ; 371,0$ e 817,6 e a produção máxima, $3.084,2 ; 3.669,6 ; 3.584,1 ; 2.701,0$ e $3.572,3$. 
No primeiro ano (Tabela 5), a dose de $\mathrm{N}$ associada a $80 \%$ da produção máxima de forragem foi de 88 e de $78 \mathrm{~kg} / \mathrm{ha} /$ corte, correspondente à PMS de 2.769 e $3.202 \mathrm{~kg} \mathrm{~N} / \mathrm{ha} /$ corte, respectivamente, para a uréia e o nitrato de amônia. No segundo ano, foi de 91 e de $116 \mathrm{~kg} \mathrm{~N} / \mathrm{ha} /$ corte, com PMS de 2.312 e $3.072 .8 \mathrm{~kg} / \mathrm{ha} /$ corte, na mesma ordem anterior. A redução na produtividade está relacionada, em parte, à menor precipitação no segundo ano.

Nas Figuras 1 e 2 são apresentadas, respectivamente, para os anos agrícolas de 1998-1999 e 1999-2000, as médias obtidas por quadrados mínimos da PMS, dos teores de MS, PB e FDN, da DIVMS e do teor de $\mathrm{N}-\mathrm{NO}_{3}$ do capimcoastcross, considerando as cinco doses de $\mathrm{N}$, as duas fontes de $\mathrm{N}$ e os cinco cortes consecutivos. Com exceção dos teores de FDN e de MS, observaram-se, nos dois anos agrícolas, em comparação à produção obtida no tratamento testemunha, acréscimos em todas as variáveis analisadas, o que indica resposta positiva do capim-coastcross às duas fontes de $\mathrm{N}$.

Observa-se nas Figuras 1 e 2 que, embora existam variações que dependem da dose e do corte, a superioridade do nitrato de amônia em relação à uréia é predominante em todas as variáveis. Na PMS, entre as doses de 50 e $200 \mathrm{~kg}$ $\mathrm{N} / \mathrm{ha}$ /corte, a superioridade do nitrato de amônia ocorreu nos dois anos. No primeiro corte do ano agrícola de 1998 1999, as médias estimadas tiveram o padrão de resposta modificado, provavelmente em conseqüência do déficit hídrico no período, o que favoreceu o nitrato de amônia, acentuando as diferenças entre as fontes na dose de $\mathrm{N}$ mais elevada.
Essa falta de consistência nas diferenças entre as fontes provavelmente está associada à complexidade da dinâmica do $\mathrm{N}$ nativo no solo e proveniente da adubação nitrogenada, cuja disponibilidade é afetada por múltiplos fatores. $\mathrm{Na}$ dose de $\mathrm{N}$ mais elevada, exceto no corte 1 , as diferenças entre as fontes não ocorreram, provavelmente porque as plantas adubadas com o nitrato de amônia já haviam alcançado o potencial máximo de produção na dose anterior (Figuras 1 e 2).

A superioridade do nitrato de amônia é explicada pelas menores perdas de $\mathrm{N}$ por volatilização na forma de amônia (Primavesi et al., 2001). A superioridade do nitrato de amônia sobre a uréia também foi constatada por Wilkinson \& Langdale (1974) em trabalho com coastal bermuda grass. Segundo esses autores, a redução na resposta para a uréia é conseqüência das elevadas perdas de amônia quando a uréia é convertida, pela urease, em $\left(\mathrm{NH}_{4}\right)_{2} \mathrm{CO}_{3}$, o qual, sendo instável, se decompõe em $\mathrm{NH}_{3}$ e $\mathrm{CO}_{2}$. Também de acordo com Whitehead (1995), a resposta das forrageiras à adubação com uréia é freqüentemente menor que a adubação com nitrato de amônia, em razão da volatilização da amônia da uréia.

Houve redução significativa no teor de MS com o aumento das doses de $\mathrm{N}$ (Figuras 1 e 2). As médias variaram de $30,6 \%$ no tratamento testemunha a $21,2 \%$ na dose de $200 \mathrm{~kg} \mathrm{~N} / \mathrm{ha} /$ corte (1998-1999) e de 35,5 a $21,9 \%$ (1999-2000). Houve diferença $(\mathrm{P}<0,05)$ entre fontes nos dois anos e a forrageira adubada com uréia apresentou os maiores teores de MS. Segundo Bailey (1973), adubações com doses elevadas de $\mathrm{N}$ aumentam o teor de água na forragem.

Tabela 5 - Produção de MS ( $\hat{Y})$ em função de doses de N ( $D=0,25,50,100$ e $200 \mathrm{~kg} \mathrm{~N} / \mathrm{ha}$ ) para uréia (1) ou nitrato de amônia (2), dentro de cortes, nos anos 1998-1999 e 1999-2000

Table 5 - DM yield $(Y)$ of coastcross grass as a function of five rates of $N(D=0,25,50,100$, and $200 \mathrm{kgN} / \mathrm{ha}$ ) of two sources: urea (1) or ammonium nitrate (2), within cuts and two years: 1998-1999 and 1999-2000

\begin{tabular}{lccc}
\hline $\begin{array}{l}\text { Corte } \\
\text { Cut }\end{array}$ & $\begin{array}{c}\text { Fonte de } \\
\text { N source }\end{array}$ & $\begin{array}{c}\text { Ano: } 1998-1999 \\
\text { Year: } 1998-1999\end{array}$ & $\begin{array}{c}\text { Ano: } 1999-2000 \\
\text { Year: } 1999-2000\end{array}$ \\
\hline 1 & 1 & $\hat{\mathrm{Y}}=4,794+6,4906 \mathrm{D}$ & $\hat{\mathrm{Y}}=366,00+9,8295 \mathrm{D}$ \\
& 2 & $\hat{\mathrm{Y}}=11,075 \mathrm{D}+0,0459 \mathrm{D}^{2}$ & $\hat{\mathrm{Y}}=44,2908+31,8874 \mathrm{D}-0,08362 \mathrm{D}^{2}$ \\
& 1 & $\hat{\mathrm{Y}}=446,83+45,99496 \mathrm{D}-0,1112 \mathrm{D}^{2}$ & $\hat{\mathrm{Y}}=269,27+15,3535 \mathrm{D}$ \\
3 & 2 & $\hat{\mathrm{Y}}=552,41+58,8822 \mathrm{D}-0,1960 \mathrm{D}^{2}$ & $\hat{\mathrm{Y}}=106,47+49,4691 \mathrm{D}-0,1717 \mathrm{D}^{2}$ \\
& 1 & $\hat{\mathrm{Y}}=587,97+21,6891 \mathrm{D}-0,06818 \mathrm{D}^{2}$ & $\hat{\mathrm{Y}}=1077,46+28,8384 \mathrm{D}-0,08921 \mathrm{D}^{2}$ \\
4 & 2 & $\hat{\mathrm{Y}}=466,25+41,8935 \mathrm{D}-0,1619 \mathrm{D}^{2}$ & $\hat{\mathrm{Y}}=1098,94+38,5386 \mathrm{D}-0,1494 \mathrm{D}^{2}$ \\
& 1 & $\hat{\mathrm{Y}}=2201,01+42,4199 \mathrm{D}-0,1338 \mathrm{D}^{2}$ & $\hat{\mathrm{Y}}=234,72+28,1799 \mathrm{D}-0,1028 \mathrm{D}^{2}$ \\
5 & 2 & $\hat{\mathrm{Y}}=2439,78+47,8441 \mathrm{D}-0,1738 \mathrm{D}^{2}$ & $\hat{\mathrm{Y}}=371,01+38,5927 \mathrm{D}-0,1598 \mathrm{D}^{2}$ \\
& 1 & $\hat{\mathrm{Y}}=734,74+32,3034 \mathrm{D}-0,1004 \mathrm{D}^{2}$ & $\hat{\mathrm{Y}}=716,88+35,6108 \mathrm{D}-0,1127 \mathrm{D}^{2}$ \\
Geral & $\hat{\mathrm{Y}}=852,28+40,7780 \mathrm{D}-0,1545 \mathrm{D}^{2}$ & $\hat{\mathrm{Y}}=817,59+38,6575 \mathrm{D}-0,1356 \mathrm{D}^{2}$ \\
Overall & 2 & $\hat{\mathrm{Y}}=800,24+29,5505 \mathrm{D}-0,08175 \mathrm{D}^{2}$ & $\hat{\mathrm{Y}}=487,87+26,8692 \mathrm{D}-0,07512 \mathrm{D}^{2}$ \\
& 1 & $\hat{\mathrm{Y}}=865,20+40,0947 \mathrm{D}-0,1281 \mathrm{D}^{2}$ & $\hat{\mathrm{Y}}=529,19+36,2699 \mathrm{D}-0,1240 \mathrm{D}^{2}$ \\
\hline
\end{tabular}


De acordo com Black (1968), se o suprimento de $\mathrm{N}$ e outros fatores permitirem o crescimento da planta, a tendência é que essa planta utilize os carboidratos disponíveis para formar células e protoplasma. As células, nessas condições, tendem a ser grandes e de pouca espessura. Segundo Bailey (1973), a parede celular contém o mais baixo teor de água, enquanto o protoplasma pode conter até $95 \%$ de água.
Nesta pesquisa, com o aumento das doses das duas fontes de adubo nitrogenado nos dois anos, houve incremento no teor de PB da forragem (Figuras 1 e 2), que variaram de 12,2 decagramas (dag)/kg no tratamento testemunha a $19,8 \mathrm{dag} / \mathrm{kg}$ na maior dose de $\mathrm{N}$ aplicada. Mesmo no tratamento sem adubação nitrogenada, o teor de PB ficou acima do nível crítico de $7 \mathrm{dag} / \mathrm{kg}$, limitante do consumo pelos
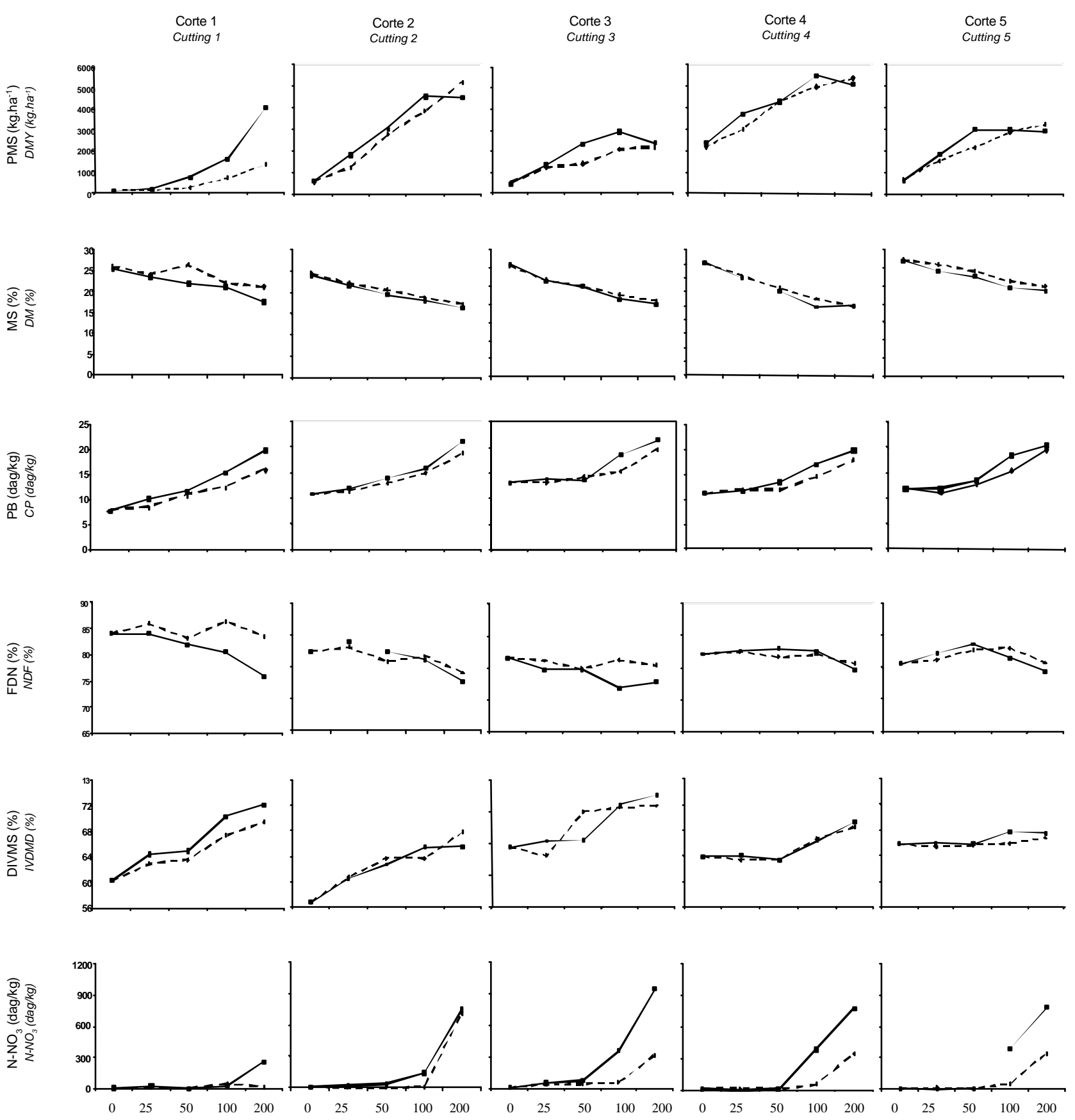

Figura 1 - Médias obtidas por quadrados mínimos considerando cinco doses de N (0,25,50,100 e $200 \mathrm{~kg} / \mathrm{ha}$ ), produção de matéria seca (PMS), teores de MS, PB e FDN, digestibilidade in vitro da MS (DIVMS) e teor de nitrato ( $\mathrm{N}^{-N_{3}}$ ) do capim-coastcrossadubado com duas fontes de N: uréia (-------) e nitrato de amônia (_

Figure 1- Least square means as a function of five rates of $N(0,25,50,100$ and $200 \mathrm{~kg} / \mathrm{ha}$ ) of DM yield (DMY), concentrations of DM, CP and NDF, in vitro DM digestibility (IVDMD) and concentration of nitrate $\left(\mathrm{N}-\mathrm{NO}_{3}\right)$ of coastcross, considering two $\mathrm{N}$ sources: urea (--------) and ammonium nitrate (_) in five cuttings (C1 to C5) during 1998-1999. 
bovinos. Esse fato é explicado pelo manejo de corte adotado, com períodos relativamente curtos de rebrota (em média de 30 dias), o que proporcionou forragem de melhor qualidade. Esse manejo, associado aos altos níveis de $\mathrm{N}$, também permitiu obter níveis elevados de PB na forragem, que podem atender a requerimentos de animais de elevada produção, como sugeriram Vilela et al. (1996). A adubação com nitrato de amônia resultou em amostras com teores de $\mathrm{PB}$, que variaram de 15,3 a 14,7 dag/kg, valores ligeiramente superiores aos obtidos nas amostras adubadas com uréia (14,3 a 13,4 dag/kg). Todavia, o rápido aumento no teor de $\mathrm{N}$ não-protéico (Figuras 1 e 2) observado com a aplicação de $100 \mathrm{~kg}$ N/ha/corte sugere que a maior fração de proteína verdadeira na planta ocorre até doses de $100 \mathrm{~kg} \mathrm{~N}$ ha/corte, com valores de 11,0 a 16,3 dag/kg de PB.

Esse fato pode ter implicações na nutrição animal, pois o N solúvel, nítrico ou orgânico, não é eficientemente
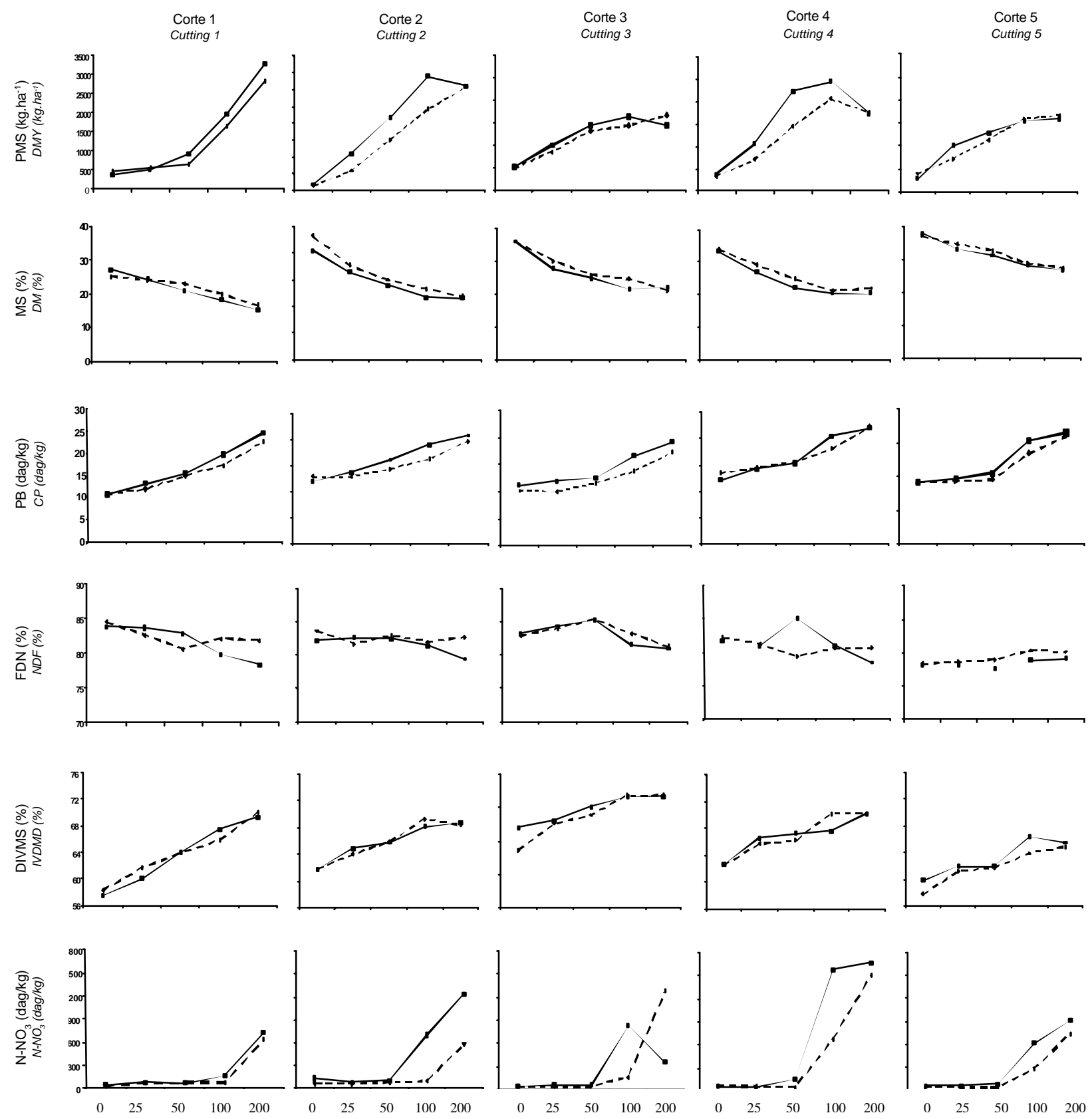

Figura 2 - Médias obtidas por quadrados mínimos considerando cinco doses de N (0,25,50, 100 e $200 \mathrm{~kg} / \mathrm{ha})$, produção de matéria seca (PMS), teores de MS, PB e FDN, digestibilidade in vitro da MS (DIVMS) e teor de nitrato ( $\mathrm{N}^{-\mathrm{NO}_{3}}$ ) do capim-coastcrossadubado com duas fontes de N: uréia (--------) e nitrato de amônia —_ ), em cinco cortes (C1 a C5), em 1999-2000.

Figure 2- Least square means as a function of five rates of $N\left(0,25,50,100\right.$, and $\left.200 \mathrm{~kg} \mathrm{ha}^{-1}\right)$ of DM yield (DMY), concentrations of DM, CP and NDF, in vitro DM digestibility (IVDMD) and concentration of nitrate $\left(\mathrm{N}-\mathrm{NO}_{3}\right)$ of coastcross, considering two $\mathrm{N}$ sources: urea (----------) and ammonium nitrate (- ) in five cuttings (C1 to C5) during 1999-2000. 
transformado em proteína microbiana pelos microrganismos do rúmen, exceto quando a dieta tem suplementação energética (Salette, 1982).

Teores elevados de PB em capim-coastcross sob adubação intensiva também foram verificados por Alvim et al. (1996), que relataram valores em torno de $20 \mathrm{dag} / \mathrm{kg}$ de PB. Resultados semelhantes também foram encontrados por Palhano \& Haddad (1992), em capim-coastcross, e por Alvim et al. (1999), em capim-tifton 85.

Os valores de FDN, de modo geral, foram elevados. As médias obtidas da adubação com uréia e com nitrato de amônia, independentemente das doses e dos cortes, foram de 81,8 e $81,1 \%$, respectivamente, superiores às encontradas por Alvim et al. (1996), Palhano \& Haddad (1992) e Rocha et al. (2001). Todavia, as plantas do gênero Cynodon são caracterizadas pela alta proporção de FDN (apenas eventualmente apresentam valores inferiores a $75 \%$ ), no entanto, possuem teores de lignina relativamente baixos, o que lhes confere boa qualidade de forragem, evidenciada pelos bons ganhos de peso de animais em pastejo nessas gramíneas. Pedreira (1996) encontrou teores de FDN de 80,8\% em capim-tifton 85 adubado com $150 \mathrm{~kg}$ N/ha/corte. Cruz et al. (2001) e Rodrigues et al. (2001) encontraram teores de FDN superiores a $81 \%$ em amostras de capim-coastcross adubado.

Redução significativa $(\mathrm{P}<0,05)$ foi observada nos teores de FDN com o aumento das doses de $\mathrm{N}$ das duas fontes. As médias (em \%) obtidas com a adubação com uréia e nitrato de amônia, analisadas como efeitos principais, nos tratamentos com 0 e $200 \mathrm{~kg}$ de $\mathrm{N}$, foram, respectivamente, de $82,1 \pm 0,26$ e 79,4 $\pm 0,26$ (ano 19981999) e de 82,4 $\pm 0,29$ e 80,3 \pm 0,29 (ano 1999-2000). Segundo Whitehead (1995), altas doses de $\mathrm{N}$ podem causar redução nos teores de celulose e lignina nas plantas forrageiras. Diminuição no teor de FDN com a adubação nitrogenada também foi constatada por Alvim et al. (1996) e Rocha et al. (2001).

Segundo Black (1968), o N disponível estimula o crescimento das plantas e aumenta a utilização dos carboidratos disponíveis para formação de células e de protoplasma, em vez de provocar o espessamento das paredes das células pelo acúmulo desses carboidratos.

As médias (em \%) dos valores de DIVMS obtidas com uréia no primeiro e segundo anos foram, respectivamente, de 65,7 $\pm 0,21$ e 64,3 \pm 0,14 e com nitrato de amônia, de 66,2 $\pm 0,21$ e $64,7 \pm 0,14$, e não foram influenciadas ( $\mathrm{P}>0,05)$ pelas fontes de adubo nitrogenado. Segundo Hamilton et al. (1970), valores de DIVMS em torno de $65 \%$ são indicativos de bom valor nutritivo e permitem consumo adequado de energia digestível.
Desse modo, apesar de os valores de FDN do capimcoastcross terem sido elevados, provavelmente a parede celular apresentava boa qualidade, em virtude do curto período de rebrota e da adubação elevada. Segundo Nussio et al. (1998), plantas forrageiras nos estádios iniciais de crescimento apresentam alta digestibilidade de folhas e hastes, haja vista a maior proporção de conteúdo celular e a alta digestibilidade da parede celular.

Valores elevados de DIVMS em forragem de capimcoastcross foram constatados por Palhano \& Haddad (1992) em capins colhidos com quatro semanas e adubado com $250 \mathrm{~kg} \mathrm{~N} / \mathrm{ha}$. Mesmo aos 33 dias de crescimento, os valores de DIVMS foram superiores a 65\%. Esses autores constataram, no entanto, acentuada redução na DIVMS quando o período de rebrota foi mais longo, fato justificado pelos aumentos da lignificação, da relação haste:folha e da proporção da parede celular.

As médias de DIVMS variaram de $61,5 \%$ no tratamento testemunha a $66,1 \%$ nas amostras das plantas adubadas com a maior dose de $\mathrm{N}$. Esse acréscimo $(\mathrm{P}<0,05)$ indica que a adubação nitrogenada proporciona aumento da DIVMS. Esse aumento de DIVMS com a intensificação da adubação nitrogenada está de acordo com a correspondente redução do teor de FDN (Figuras 1 e 2), o que também foi observado por Nascimento \& Pinheiro (1975). Todavia, na literatura, os resultados são conflitantes quanto às variações de DIVMS com a adubação nitrogenada. Cáceres et al. (1989), Nussio et al. (1998) e Rocha et al. (2001) não constataram esse efeito na DIVMS do capimcoastcross. Entretanto, Monson \& Burton (1982) notaram incremento da DIVMS de cinco espécies e de híbridosde Cynodon com o aumento das doses de N. Ruggieri et al. (1995), embora utilizando doses de N mais baixas, verificaram aumento da DIVMS nas folhas de Brachiaria brizantha cv. Marandu. Ford \& Williams (1972) observaram incremento da DIVMS de Digitaria decumbens e Setaria anceps cultivadas sob diferentes níveis de N.

Segundo Ford \& Williams (1972), altas doses de N, em comparação a doses baixas, devem proporcionar em determinado tempo maior proporção de forragem nova em relação ao resíduo das plantas, o que provavelmente ocorreu neste trabalho, no qual foram associados níveis altos de $\mathrm{N}$ e períodos curtos de rebrota.

Em todos os cortes, verificou-se aumento significativo $(\mathrm{P}<0,05)$ no teor de $\mathrm{N}$-nitrato na planta, à medida que as doses de $\mathrm{N}$ aumentaram (Figuras 1 e 2). Esse efeito foi mais acentuado em alguns cortes de plantas que receberam nitrato de amônia. Esse fato é explicado pelas menores perdas de $\mathrm{N}$ por volatilização nessas parcelas e, portanto, pela maior oferta de $\mathrm{N}$-nitrato do solo para as plantas (Primavesi et al., 2001). 
$\mathrm{O}$ nitrato é a única forma inorgânica de $\mathrm{N}$ que se acumula na planta quando o suprimento desse elemento excede o requerimento para o crescimento. Fatores restritivos à fotossíntese, mas não à absorção, também podem provocar acúmulo de nitrato. De modo geral, o aumento do teor de $\mathrm{N}$-nitrato foi mais acentuado nas doses iguais ou superiores a $100 \mathrm{~kg} \mathrm{~N} / \mathrm{ha} /$ corte, quando a resposta em produção foi menos acentuada, principalmente para o nitrato de amônia.

O teor de $\mathrm{N}$-nitrato pode atingir níveis tóxicos na dieta de bovinos. Segundo Pratt et al. (1976), o nível considerado seguro é de aproximadamente 0,21 dag/kg. Excesso de nitrato é convertido no rúmen em nitrito, que, absorvido, converte a hemoglobina do sangue em metamoglobina, a qual não é capaz de transportar oxigênio (Walton, 1983). De acordo com Whitehead (1995), existem evidências de que a concentração tóxica de nitrato para bovinos varia com a dieta. O nível de $\mathrm{N}$-nitrato considerado tóxico em forragem pastejada $(0,35$ a $0,45 \mathrm{dag} / \mathrm{kg})$ é mais elevado que naquela utilizada como silagem ou feno, em razão da menor taxa de liberação do nitrato pela forragem fresca e também do maior tempo requerido para a ingestão da forragem sob pastejo.

Segundo Whitehead (1995), quando o N é aplicado em doses baixas em pastagem deficiente em $\mathrm{N}$, ocorre aumento na produção, mas a concentração do nutriente na planta é pouco alterada. Verifica-se nas Figuras 1 e 2 que, mesmonas doses mais elevadas de $\mathrm{N}$ e com períodos de rebrota relativamente curtos, os teores de $\mathrm{N}$-nitrato na planta não atingiram níveis considerados tóxicos para bovinos, o que comprova a boa eficiência do uso do N pelo capim-coastcross. Os teores de $\mathrm{N}$-nitrato mais elevados na forragem foram, em média, de $0,1 \mathrm{dag} / \mathrm{kg}$.

Vicente-Chandler et al. (1959), em avaliações de forrageiras tropicais colhidas a cada 60 dias, encontraram apenas traços de nitrato na forragem, mesmo com dose de $896 \mathrm{~kg} \mathrm{~N} / \mathrm{ha} / \mathrm{ano}$. Olsen et al. (1972), no entanto, trabalhand o com quatro gramíneas tropicais, encontraram níveis potencialmente tóxicos na forragem nas doses de $\mathrm{N}$ mais elevadas. Segundo Wilkinson \& Langdale (1974), o acúmulo de nitrato em níveis tóxicos em plantas do gênero Cynodon parece não ocorrer mesmo com aplicações de doses elevadas de N.

Segundo Salette (1982), os riscos de atingir teores tóxicos de nitrato são baixos, mesmo em pastagens com forrageiras de clima temperado adubadas com até $400 \mathrm{kgN} /$ ha/ano de forma parcelada, pois o N-nitrato raramente atinge o teor de $0,25 \mathrm{dag} / \mathrm{kg}$.

\section{Conclusões}

A adubação nitrogenada em capim-coastcross emdoses de até $200 \mathrm{~kg} \mathrm{~N} / \mathrm{ha}$ por corte a cada 30 dias aumenta a produção de $\mathrm{MS}$, o teor de $\mathrm{PB}$, a digestibilidade in vitro da MS e o teor de nitrato e ainda reduz o teor de MS e FDN.

O nitrato de amônia é superior à uréia na produção de MS, e seus efeitos podem variar conforme as doses de nitrogênio e a sucessão de cortes.

\section{Literatura Citada}

ALVIM, M.J.; RESENDE, H.; BOTREL, M.A. Efeito da freqüência de cortes e de níveis de nitrogênio sobre a produção e qualidade da matéria seca do "coastcross". In: WORKSHOP SOBRE O POTENCIAL FORRAGEIRO DO GÊNERO CYNODON, 1996, Juiz de Fora. Anais... Juiz de Fora: EMBRAPA CNPGL, 1996. p.45-55.

ALVIM, M.J.; XAVIER, D.F.; BOTREL, M.A. et al. Resposta do Coastcross (Cynodon dactylon) a diferentes doses de nitrogênio e freqüências de corte. Revista Brasileira de Zootecnia, v.27, n.5, p.833-840, 1998.

ALVIM, M.J.; XAVIER, D.F.; VERNEQUE, R. et al. Resposta do Tifton 85 a doses de nitrogênio e intervalos de cortes. Pesquisa Agropecuária Brasileira, v.34, n.12, p.2345-2352, 1999.

BAILEY, R.W. Water in herbage. In: BUTLER, G.W.; BAILEY, R.W. (Eds.) Chemistry and biochemestry of herbage. London: Academic Press, 1973. p.13-24.

BLACK, C.A. Soil-plant relationship. New York: John Wiley, 1968. p.507-557.

CÁCERES, O.; SANTANA, H.; DELGADO, R. Influencia de la fertilización nitrogenada sobre el valor nutritivo y rendimiento de nutrimentos. Pastos y Forrages, v.12, n.2, p.189-195, 1989.

CRUZ, G.M.; RODRIGUES, A.A.; TULLIO, R.R. et al. Avaliação do desempenho de bezerros Nelore e cruzados desmamados recebendo dois níveis de suplementação concentrada em pastagens de coastcross. In: REUNIÃO ANUAL DA SOCIEDADE BRASILEIRA DE ZOOTECNIA, 38., 2001, Piracicaba. Anais... Piracicaba: Sociedade Brasileira de Zootecnia, 2001. p.11811182.

FORD, C.W.; WILLIAMS, W.T. In vitro digestibility and carbohydrate composition of Digitaria decumbens and Setaria anceps growth at different levels of nitrogenous fertilizer. Australian Journal Agricultural Research, v.24, p.309316, 1973.

GOMES, J.F.; SIEWERDT, L.; SILVEIRA JR., P. Avaliação da produtividade e economicidade do feno de capim pangola (Digitaria decumbens Stent) fertilizado com nitrogênio. Revista da Sociedade Brasileira de Zootecnia, v.16, n.6, p.491-499, 1987

GOMIDE, J.A.; COSTA, G.G. Adubação nitrogenada e consorciação de capim-colonião e capim-jaraguá. III. Efeitos de níveis de nitrogênio sobre a composição mineral e digestibilidade da matéria seca das gramíneas. Revista da Sociedade Brasileira de Zootecnia, v.13, n.2, p.215-224, 1984.

HAMILTON, R.I.; LAMBOURNE, L.J.; ROE, R. et al. Quality of tropical grasses for milk production. In: INTERNATIONAL GRASSLAND CONGRESS., 11., 1970, Surfers Paradise. Proceedings... Surfers Paradise: [s.n.], 1970. p.860-864.

LITTELL, R.C.; HENRY, P.R.; AMMERMAN, C.B. Statistical analysis of repeated measures data using SAS procedures. Journal of Animal Science, v.76, p.1216-1231, 1998. 
LITTELL, R.C.; MILLIKEN, G.A.; STROUP, W.W. et al. SAS system for mixed models. Cary: Statistical Analysis System Institute, 1996. 633p.

MELLO, F.A.F. Uréia fertilizante. Campinas: Fundação Cargill, 1987. 192p

MONSON, W.G.; BURTON, G.W. Harvest frequency and fertilizer effects on yield, quality and persistence of eight bermuda grasses. Agronomy Journal, v.74, n.2, p.371-374, 1982.

NASCIMENTO JR., D.; PINHEIRO, J.S. Valor nutritivo do capimjaraguá em diferentes idades. Revista da Sociedade Brasileira de Zootecnia, v.4, n.1, p.101-113, 1975.

NUSSIO, L.G.; MANZANO, R.P.; PEDREIRA, C.G.S. Valor alimentício em plantas do gênero Cynodon. In: SIMPÓSIO SOBRE MANEJO DE PASTAGENS, 15., 1998, Piracicaba. Anais... Piracicaba: Fundação de Estudos Agrários Luiz de Queiroz, 1998.p.203-242.

OLSEN, F.J. Effect of large application of nitrogen fertilizer on the productivity and protein content of four tropical grasses in Uganda. Tropical Agricultural, v.49, n.3, p.251/260, 1972.

PALHANO, A.L.; HADDAD, C.M. Exigências nutricionais e valor nutritivo de Cynodon dactylon (L.) Pers. cv. coastcross no 1 . Pesquisa Agropecuária Brasileira, v.27, n.10, p.1429$1438,1992$.

PEDREIRA, C.G.S. Avaliação de novas gramíneas do gênero Cynodon para a pecuária do sudeste dos Estados Unidos. In: WORKSHOP SOBRE O POTENCIAL FORRAGEIRO DO GÊNERO CYNODON, 1996, Juiz de Fora. Anais... Juiz de Fora: EMBRAPA-CNPGL, 1996. p.111-125.

PRATT, P.F.; DAVIS, S.; GHARPLESS, R.G. et al.Nitrate contents of sudangrass and barley grown on plots treated with animal manures. Agronomy Journal, v.68, p.311-314, 1976.

PRIMAVESI, O.; CORRÊA, L.A.; PRIMAVESI, A.C. et al. Adubação com uréia em pastagem deCynodon dactyloncv. Coastcross: eficiência e perdas. São Carlos: Embrapa Pecuária Sudeste, 2001. 42p. (Circular Técnica, 30).

ROCHA, G.P.; EVANGELISTA, R.L.; LIMA, A.J. Nitrogênio na produção de matéria, teor e rendimento de proteína bruta de gramíneas tropicais. In: REUNIÃO ANUAL DA SOCIEDADE BRASILEIRA DE ZOOTECNIA, 38., 2001, Piracicaba. Anais... Piracicaba: Sociedade Brasileira de Zootecnia, 2001. p.68-69. (CD-ROM).

RODRIGUES, A.A.; CRUZ, G.M.; ALENCAR, M.M. et al Desempenho de novilhas de diferentes grupos genéticos, suplementadas ou não, em pastagens de coastcross. In REUNIÃO ANUAL DA SOCIEDADE BRASILEIRA DE ZOOTECNIA, 38., 2001, Piracicaba. Anais... Piracicaba: Sociedade Brasileira de Zootecnia, 2001. p.1155-1157.

RUGGIERI, A.C.; FAVORETTO, V.; MALHEIROS, E.B. Efeito de níveis de nitrogênio e regimes de corte na distribuição, na composição bromatológica e na digestibilidade "in vitro" da matéria seca da Brachiaria brizantha (Hochst) Stapf cv. marandu. Revista da Sociedade Brasileira de Zootecnia, v.24, n.1, p.20-30, 1995.
SALETTE, J. The role of fertilizer in improving herbage quality and optimization of its utilization. In: INTERNATIONAL POTASH INSTITUTE, 12., 1982, Goslar. Proceedings... Bern: Der Bund, 1982. p.117-144.

SILVA, D.J. Análise de alimentos: métodos químicos e biológicos. Viçosa, MG: Universidade Federal de Viçosa, 1981. 166p.

SOUZA, G.B.; NOGUEIRA, A.R.; BATISTA, L.A.R. Método alternativo para determinação de fibra em detergente neutro e detergente ácido. São Carlos: Embrapa Pecuária Sudeste, 1999. 21p. (Boletim de Pesquisa, 4).

TEDESCO, M.J.; VOLKWEISS, S.J.; BOHNEN, H. Análises de solo, plantas e outros minerais. Porto Alegre: Universidade Federal do Rio Grande do Sul, 1985. 188p. (Boletim Técnico de Solos, 5).

VICENTE-CHANDLER, J.; SILVA, S.; FIGARELLA, J. The effect of nitrogen fertilization and frequency of cutting on the yield and composition of three tropical grasses. Agronomy Journal, v. 51, n.4, p. $202-206,1959$

VILELA, D.; ALVIM, M.J.; CAMPOS, O.F. et al. Produção de leite de vacas holandesas em confinamento ou em pastagem de coastcross. Revista da Sociedade Brasileira de Zootecnia, v.25, n.6, p.1228-1244, 1996.

WALTON, P.D. Production \& management of cultivated forages. Reston: Prentice-Hall, 1983. p.336.

WERNER, J.C.; PEDREIRA, J.V.S.; CAIELE, E.L. Estudo de parcelamento e níveis de adubação nitrogenada com capimpangola (Digitaria decumbens Stent). Boletim da Indústria Animal, v.24, p.147-151, 1977.

WHITEHEAD, D.C. Grassland nitrogen. Wallingford: CAB International, 1995. 397p.

WILKINSON, S.R.; LANGDALE, G.W. Fertility needs of the warmseason grasses. In: MAYS, D.A. (Ed.) Forage fertilization. Madison: American Society of Agronomy. Crop Science Society of America; Soil Science Society of America, 1974. p.119-145.

WOLFINGER, R. Covariance structure selection in general mixed models. Communications in statistics simulation and computation, v.22, n.4, p.1079-1106, 1993. 